\title{
AN IT MODEL OF A KNOWLEDGE MAP WHICH SUPPORTS MANAGEMENT IN SMALL AND MEDIUM-SIZED COMPANIES USING SELECTED POLISH CONSTRUCTION ENTERPRISES AS AN EXAMPLE
}

\author{
Bożena HOŁA ${ }^{\mathrm{a}}$, Marek SAWICKI ${ }^{\mathrm{a}}$, Mirosław SKIBNIEWSKI ${ }^{\mathrm{b}}$ \\ ${ }^{a}$ Faculty of Civil Engineering, Wrocław University of Technology, \\ ul. Wybrzeże Wyspiańskiego 27, 50-370 Wroctaw, Poland \\ ${ }^{b}$ Department of Civil \& Environmental Engineering, University of Maryland, \\ College Park, MD 20742-3021, USA
}

Received 09 Oct 2013; accepted 02 Dec 2014

\begin{abstract}
Knowledge is one of the most important resources of an enterprise. Skillful knowledge management can bring significant benefits including labour productivity growth, an increase in quality of provided services and also a strengthening of the competitive position of an enterprise. This paper presents an IT model of a Knowledge Map which supports knowledge management in a construction enterprise. The model was developed on the basis of the results of surveys and analyses carried out in small and medium sized construction enterprises in Poland. The process approach in management was included in the proposed model and it involves analysis of an enterprise activity as a set of processes. The model contains processes occurring at enterprise level and also in the widely considered investment process in the construction industry. This assumption made the proposed Knowledge Map universal and able to be applied in construction enterprises operating in both the design and executive field.
\end{abstract}

Keywords: civil engineering, knowledge management, Knowledge Map, process approach, investment process, enterprise.

\section{Introduction}

In the era of the wide use of IT technology and the phenomenon of globalization occurring in the economy, skillful and rapid exchange of information and experiences gain significant meaning. In this situation the ability of sharing knowledge is the strength of an enterprise, and a management system, based on knowledge, is a tool which supports the management of an enterprise. The implementation of such a system is meant to encourage enterprise innovation which involves continuous improvement, introduction of new products, services, technologies and methods of work organization. Such a system encourages creativity in people and also enables the transformation of their knowledge and ideas into innovative solutions.

Managers of enterprises have recognized that employee knowledge is an important resource and that its loss may lead to the collapse of a company's operation. Investing in skills of employees and making them share knowledge is beneficial for both sides. However, the acquisition of knowledge is a long process. Knowledge resources, in the form of thousands of unclassified components (data, information, experiences), can become a problem in the area of their interpretation. Systematic se- lection of knowledge elements, verification, and registration for the purpose of later mapping are as important as the creation itself.

The paper presents the IT model of a Knowledge Map - a tool which aids knowledge management in a construction enterprise. The process approach in management was included in the proposed model and it involves analysis of enterprise activity as a set of processes. Based on surveys and audits conducted in construction enterprises, the area of knowledge crucial for the management of an enterprise was specified, the structure of the Knowledge Map was proposed and an IT model enabling the practical application of the map was presented.

\section{Problem description}

Construction enterprises in Poland operate in a rapidly changing and highly competitive environment. Such a situation requires from enterprises big flexibility and ability in the area of adjusting to changing conditions. In order to maintain and even to improve the position of an enterprise on the construction market it is necessary to use methods that support management (Bitarafan et al. 2013; Czarnigowska, Sobotka 2013; Jaskowski, Sobotka 2012;

Corresponding author: Bożena Hoła

E-mail: bozena.hola@pwr.wroc.pl 
Kaklauskas et al. 2013; Negahban et al. 2012; Lin 2013; Koulinas, Anagnostopoulos 2013; Zavadskas et al. 2010, 2011, 2013; Staniūnas et al. 2013).

The development of such methods and tools is particularly important for the construction industry, which in contrast to other sectors of the economy is characterized by: high diversity and uniqueness of executed building structures, seasonality of works, plurality of applied technologies, frequent changes of construction sites and also volatility of the external environment (Lin 2008). Due to the large variety of constructed building structures and variability of execution conditions (technological, organizational, and legal), the course of an investment process is complicated and its management is difficult.

High turnover of staff in the Polish construction industry is a negative phenomenon. This makes experience gained while working in an enterprise disappear when key employees leave. It causes not only the loss of gained experience, but also the loss of potential innovations. As a result, enormous amounts of time and work are wasted on re-acquiring knowledge to work in different job posts and future construction projects.

When analyzing the possibilities and needs of implementing management support tools in construction enterprises in Poland, the structure of enterprises should be considered. Based on information included in the Statistical Yearbook, over 241 thousand construction companies were registered in Poland in 2012, employing in total over 640 thousand people. From this number 230 thousand construction enterprises (representing $97.75 \%$ of all construction companies) are small enterprises employing less than 19 people and 3474 are medium-sized enterprises employing 20 to 49 people. This group of enterprises is the basis of the construction industry in Poland. In total, in the sector of such enterprises work 366 thousand people which represents approximately $60 \%$ of all employees in the construction industry. It should also be highlighted that the value of production earned by small and mediumsized enterprises is equal to PLN 105986 million and represents about $70 \%$ of the total value of construction and assembly production. Therefore, it is a significant sector of construction production, which requires the support of science. Due to the often limited investment costs in enterprises of this sector there is a lack of management support tools (Hoła et al. 2012a).

It can be assumed that the development and implementation of a tool based on knowledge which aids management in small and medium-sized construction enterprises will ensure the efficient use of possessed intellectual capital, and consequently improve the market position of the company. Transfer of knowledge gained from previous investments among employees will enable the same or similar mistakes during subsequent investments to be avoided. This will shorten the time of execution of construction projects, reduce the cost of execution, improve the quality of work and reduce risk (Soares, Anderson 1997).

\section{Literature review}

Researchers conducted in many organizations among top managers indicate that an awareness of the importance of knowledge as a key intangible resource is continuously increasing (Pathirage et al. 2007; Preece et al. 2000; Forcada et al. 2012).

Davenport and Prusak (1998) define knowledge as a combination of data and information with experience, interpretation and conclusion. Nonaka and Takeuchi (1995) divide knowledge into explicit and tacit knowledge. Explicit knowledge is included in documents, standards and procedures, while tacit knowledge is the knowledge attached to people who possess it. Such knowledge disappears with staff turnover (Jemielniak, Koźminski 2012).

One of the main challenges of an organization is knowledge asset management in order to achieve competitive advantage (Kale, Karaman 2012; Cheng et al. 2012; Johannessen 2008). In the process of knowledge management several stages can be distinguished which consist of: knowledge identification, knowledge acquisition, retention, storage, development, transfer and the use of knowledge (Egbu 2006; Tserng, Lin 2004; Lin et al. 2006; Lin 2006; Dave, Koskela 2009; Arif et al. 2009). Retention of knowledge in an enterprise depends on such factors as: culture of sharing knowledge, awards and accolades for sharing knowledge, possessing a technological platform that allows the collection of large-format sets and also an awareness of managers and employees about the benefits associated with the system of knowledge retention (Arif et al. 2012). Saving, storing and processing knowledge in order to formulate conclusions regarding future projects can significantly support management processes (Maqsood et al. 2006; El-Diraby, Zhang 2006; Lin et al. 2011; Lin 2008).

Benefits from the implementation of knowledge management strategies in a large construction enterprise were studied, among others, by Preece et al. (2000) and Zhang et al. (2013). They noticed that there are problems and conflicts associated with the implementation of new management methods in enterprises in the construction industry. It is due to the nature of the construction industry, namely, the fact that a construction project environment overlaps with an enterprise environment. The implementation of knowledge management in the construction industry requires changes in an organization's culture. First of all, knowledge management must be approved at all organizational levels of an enterprise and among employees. Directions of knowledge management development in architecture, engineering and civil engineering were presented, among others, by Rezgui (2006) and Rezgui et al. (2010). Examples of knowledge management system application in large construction corporations are included, among others, in the studies of the following authors: Dave and Koskela (2009), Wu et al. (2012), Yu et al. (2009, 2010). 
A Knowledge Map is a tool used for locating knowledge and supporting knowledge management (Lin et al. 2006; Kim et al. 2003; Liu et al. 2009; Yang 2007). A Knowledge Map is defined as a graphic form of knowledge representation which illustrates the relationships between knowledge and its attributes (Kim et al. 2003). It is a consciously designed medium which enables communication between those who create knowledge and those who use it (Wexler 2001; Lee, Tserng 2006). Because knowledge is constantly changing, a Knowledge Map should be a dynamic, interactive and evolving tool (Woo et al. 2004).

The concept of using Knowledge Maps as a tool for locating knowledge resources was proposed at the end of 90's of the last century by M. Eppler. It was propagated by, among others, G. Probst, S. Raub and K. Romhardt (Galant, Perechuda 2005). Benefits for an enterprise resulting from the practical application of a Knowledge Map are very significant. Knowledge Maps facilitate the finding of information in databases, facilitate the transfer of knowledge in an organization, increase the efficiency of learning (O’Donell 1993, 1994), indicate links between documents (Xu, Ibrahim 2004; Gabrielaitis, Baušys 2006) and also facilitate many other things. Information included in Knowledge Maps can be organized according to various criteria, saved electronically and presented with the use of graphic programs. Due to this, the availability of information for many people and at any time and place is increasing.

Although the potential of a Knowledge Map application is very large, only a few industries have their own Knowledge Maps (Tserng et al. 2010). Because every field of science and industry is characterized by different specific features, it is not possible to build one universal Knowledge Map (Yin et al. 2005). In literature, examples of using Knowledge Maps in medical sciences, law, the tourism industry (Yang, Luk 2003) and also civil engineering can be found (Yin et al. 2005; Lin et al. 2006; Tserng et al. 2010). In Polish literature there are no examples of the application of Knowledge Maps in construction enterprises.

In the 90's of XX century, special attention was paid to the use of process management in the construction industry. In many studies on this subject, it was emphasized that the use of the process approach in enterprise management leads to the improvement of productivity and competitiveness of an enterprise in the construction market (Burati, Oswald 1993; Soares, Anderson 1997; Pheng, Teo 2000; Han et al. 2012). Moreover, in the process approach to management, special attention is paid to continuous improvement and achieving customer satisfaction (Tam et al. 2008; Tchidi et al. 2012).

Process management was included in the developed ISO 10006 (2005) and ISO 9001 (2008) standards. Research has shown that companies that have implemented quality management systems based on these standards achieve greater efficiency and are competitive in the market of construction works (Han et al. 2012; Haponava, Al-Jibouri 2010).
The conducted review of literature showed that management support in a construction enterprise, with the use of such a tool as a Knowledge Map, can yield significant and measurable benefits. The use of the process approach promoted by ISO 9001 (2008) standards will reinforce this effect, and further in the future facilitate the obtaining of a certificate of quality, occupational safety and environment management.

\section{Objective and methodology of research}

The aim of conducted research was to develop and implement in the selected construction enterprises an IT management support tool which is based on knowledge. The area of knowledge, which is the subject of management, is associated with the use of the process approach promoted by ISO 9001 (2008) standards. Figure 1 presents the methodology of the carried out research. Research was conducted in three stages which correspond to the gradual development of the task. It included the following activities:

Stage 1: execution of surveys and audits in construction enterprises, the analysis of obtained results and making conclusions.

Stage 2: development of a Knowledge Map model, including: building of an IT model and determining the structure of the map which considers requirements of the process approach to management.

Stage 3: Implementation of the Knowledge Map in selected construction enterprises.

\section{Research carried out in construction enterprises}

The objective of Stage 1 was to obtain information about construction enterprises which would allow the direction of further research to be determined. The research was conducted in two phases.

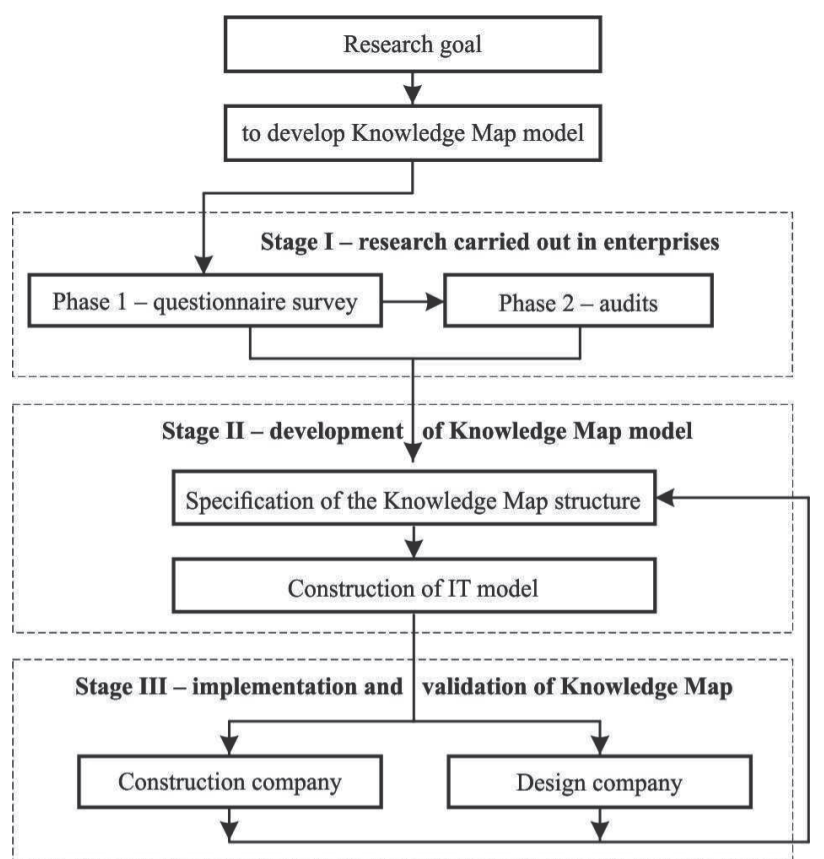

Fig. 1. Research scheme 


\subsection{Phase I - surveys}

The research questionnaire was formulated on the basis of preliminary studies carried out in several construction enterprises with the use of the direct interview method. The questionnaire includes questions about four areas related to enterprise activity, namely: A) information about an enterprise (location, business profile, business system, the number of employees); B) processes carried out in all spheres of enterprise activity; C) the scope of carried out construction activity; D) used computer software.

The questionnaire includes a set of processes which may occur in enterprises of the construction industry. They were defined on the basis of current laws and regulations. During the execution of this phase, requirements regarding processes which are included in the ISO 9001 (2008) standards were also considered. The task of respondents was to identify processes occurring in an enterprise and adding processes which have not been included in the survey but occur in an enterprise. A fragment of the formulated research questionnaire is presented in Table 1.

The research questionnaire was placed on the website of the Institute of Building Engineering of Wroclaw University of Technology (www.gmw.pwr.wroc.pl) and was also sent directly to enterprises by e-mail or by delivery by interviewers.

\subsection{Overview of survey results}

The survey was carried out in approximately 280 construction enterprises providing construction services in various areas: designing, execution of building structures, repairs and renovations.

The analysis of the surveys indicates that $63 \%$ of the surveyed enterprises are based in Lower Silesia, while $37 \%$ represent other Polish regions. 31\% are enterprises from Wroclaw. The structure of surveyed enterprises regarding the number of employed people is as follows: $40 \%$ are micro enterprises, $38 \%$ are small-sized enterprises, $12 \%$ are medium-sized enterprises and $10 \%$ are large enterprises. Further analysis of the survey shows that $65 \%$ are executive enterprises, $20 \%$ are design companies, $12 \%$ are companies providing other services related to civil engineering and $3 \%$ of surveyed companies carry out executive and design activity. Detailed data about the structure of the surveyed enterprises, due to the number of employees and the business profile, are presented in Figures 2 and 3.

Regarding the way of running a business, $28 \%$ of enterprises carry out production processes independently, $7 \%$ with the use of a contract system which means with subcontractors, and $28 \%$ with the use of a mixed system. $37 \%$ of respondents did not answer this question. Surveys were also analyzed due to responses regarding selected processes qualified for specified areas of management. Figure 4 presents a summary of selected processes in the surveyed enterprises.

The analysis of obtained data indicates that for executive and design enterprises the most important pro-

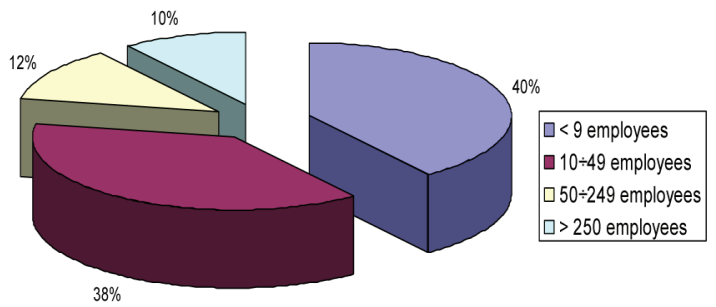

Fig. 2. Structure of enterprises according to the number of employees

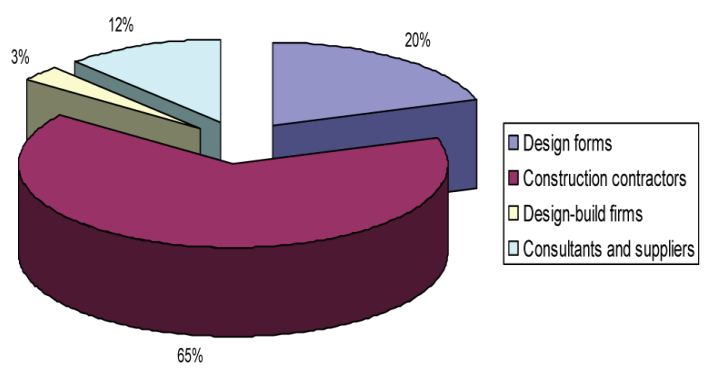

Fig. 3. Structure of enterprises according to business profile

cesses are from the area of marketing and investor services which are related to the necessity of obtaining new orders (marked: 1.1-1.6). In this case, the positive answers regarding the presence of such processes in an enterprise were equal to $85 \%$. A similar level of interest in both groups of enterprises is noted for processes from the area of general administration and personnel management (8.1-8.12).

However, in this case the level of process importance evaluation is much lower and is equal to approximately $65 \%$. In the other groups of processes, significant differences in the evaluation of importance of individual processes are noticed. This is a correct phenomenon, because it reflects the areas of activity of these enterprises. In project offices, special attention is paid to processes associated with the design of a building object and its execution (2.1-2.8), whereas in executive enterprises, issues related to the execution itself, acceptances of building works, complaints, supply of materials, etc. (5.4-5.7, $6.1,7.3)$ are emphasized. According to respondents, the least important is environmental management (8.2) and quality management (8.8). For both of these processes the level of positive answers was equal to just over $40 \%$.

Analysis of the information contained in questionnaires, due to used computer programs supporting enterprise operation, showed that construction enterprises primarily use computer programs for cost estimation (Rhodes, Norma Plus), the design of building structures (AUTOCAD) and accounting. There are no programs for process management, despite the fact that such programs are available on the market. The reason for this is that they are very expensive and small construction companies cannot afford to buy them. 
Table 1. A fragment of the research questionnaire

\section{A/ Information about an enterprise}

Enterprise name: ................

Enterprise address:

Number of employed people: ..............

Activity profile: the design office ..... executive enterprise ......... other.....

Model of running business: a) independently : ... b) contract system: ... $\quad$ c) mixed system: ...

Questionnaire completed by:

Date: ... e-mail:

Job post

B/ Please choose the management processes required in your company

Proposed names of management processes

\begin{tabular}{c|c|c|c|} 
YES & NO & Do not \\
is required & is not required
\end{tabular} Comments

\section{Processes from the area of marketing and Investor services}

\begin{tabular}{|l|l|l|l|l|l|}
\hline 1.1 & Marketing activities & & & & \\
\hline 1.2 & Risk assessment of the offered project & & & \\
\hline $1.3-1.7$ & $\ldots \ldots$. & & & & \\
\hline
\end{tabular}

2. Processes from the area of project management

\begin{tabular}{|l|l|l|l|l|l|}
\hline 2.1 & The acquisition of permits and arrangements & & & \\
\hline 2.2 & Designing a building structure & & & & \\
\hline $2.3-2.9$ & $\ldots . . .$. & & & & \\
\hline
\end{tabular}

3. Processes from the area of research and development

4. Processes from the area of purchases

5. Processes from the area of building site execution

\begin{tabular}{|l|l|l|l|l|l|}
\hline 5.1 & Hazard identification & & & & \\
\hline 5.2 & Occupational risk assessment & & & \\
\hline 5.4 & $\begin{array}{l}\text { Implementation, management and liquidation of a } \\
\text { building site }\end{array}$ & & & & \\
\hline $5.5-5.14$ & $\ldots \ldots$. & & & & \\
\hline
\end{tabular}

6. Processes from the area of sales

\begin{tabular}{|l|l|l|l|l|l|}
\hline 6.1 & Final acceptance of the construction & & & & \\
\hline 6.2 & Sale of services & & & & \\
\hline $6.3-6.5$ & $\ldots .$. & & & & \\
\hline
\end{tabular}

7. Processes from the area of finances

8. Processes from the area of general administration

\begin{tabular}{|l|l|l|l|l|l|}
\hline 8.1. & Hiring of an employee & & & & \\
\hline $8.2-8.13$ & $\ldots .$. & & & & \\
\hline
\end{tabular}

C/ Please list important works carried out in your company

\begin{tabular}{|l|c|}
\hline $\mathrm{Lp}$ & Name of works (designing or executive) \\
\hline & \\
\hline \multicolumn{2}{|c|}{ D/ Please list major computer systems used in your company } \\
\hline & \\
\hline
\end{tabular}




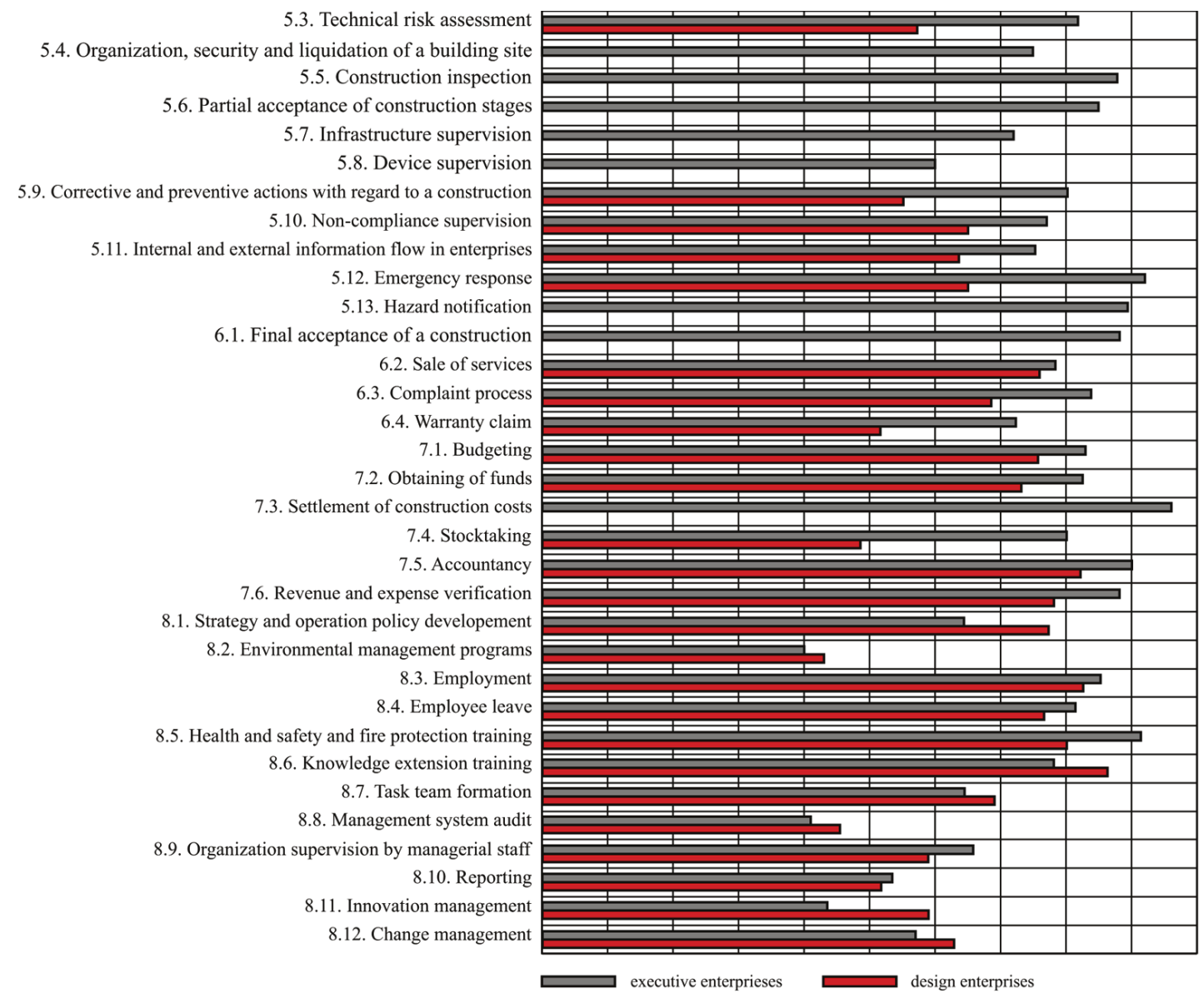

Fig. 4. A summary of processes surveyed in construction enterprises

Based on the literature review and research conducted in Phase I, it was concluded that:

- The majority of small and medium-sized construction enterprises in Poland have not yet implemented management systems because they are very expensive investments and owners cannot afford them.

- The majority of small and medium-sized construction companies are owned by people possessing extensive knowledge in the area of designing and executing building structures, and less knowledge in business management and issues related to this. In contrast to large companies, management staff are often limited to one, or at most a few people.

- In small and medium-sized enterprises there is a strong interest in process management, but knowledge about the process approach and benefits for the company coming from its practical application, is negligible.

The above conclusions were the basis of the assumption that it is necessary to support small and mediumsized construction enterprises with a simple management support tool. The developed management system will consider the process approach which involves analyzing a company's activity as a set of processes (Hoła et al. 2012a, 2012b, 2012c).

\subsection{Phase 2- audits}

In the second phase, audits were carried out in 20 enterprises from the sector of small and medium-sized construction enterprises which were selected from those that have been subjected to surveys. Research was conducted by entitled experts from the field of the implementation of a quality management system according to ISO 9001 (2008) standards.

The aim of carried out audits was to identify the organizational state of construction companies and to examine applied management processes with regards to the requirements of ISO 9001 (2008) standards. The following research techniques were used: interviews with management staff and analysis of documents. Based on the conducted research it was found, among other things, that the majority of audited enterprises do not apply any system of quality management and knowledge about the process approach to management is negligible. In the audited enterprises, special attention was paid to the supervision of the main processes related to the investment process, customer orders, processes related to finances and work safety on construction sites. An efficient course of processes from the area of auxiliary and management processes was considered to a lesser extent. Moreover, in small construction enterprises many processes are sub- 
contracted to be implemented by external entities. These are auxiliary processes such as: accounting, human resources services, IT services, device services, legal services, equipment and transport services.

After completing surveys and audits and also analysis of the obtained results, authors of the article proposed an IT model of a Knowledge Map as a management support tool for small and medium-sized construction enterprises. The main assumption of the built model was to combine the idea of a Knowledge Map with the process approach to management. In Poland, a Knowledge Map has not yet been developed for construction enterprises and this will be the first such tool designed for small and medium-sized enterprises.

\section{The developed model of a Knowledge Map}

The purpose of this stage was to develop a model of a Knowledge Map. Based on the conducted audits, the identification of domains of knowledge about a construction enterprise which relate to process management was made.

\subsection{Basis for knowledge classification in a Knowledge Map}

The classification of knowledge about an enterprise which is included in a Knowledge Map was based on the following observations:

- Every enterprise is a system located in a specific environment.

- The environment has an impact on the activity carried out in an enterprise.

- In order to conduct processes, the following appropriate material resources are necessary: people, technical means, work items and also immaterial resources which include trademarks, inventions and patents.

- System operation results in the execution of production, auxiliary and management processes.

- The knowledge required to carry out processes is contained in documents. Records of the conducted processes which are the evidence of undertaken decisions in the area of enterprise management are made during the course of processes.

- Various types of hazards and risks are connected to the execution of construction works.

- Very important for the appropriate functioning and development of an enterprise is an assessment of the carried out processes, employed people, cooperating companies and implemented projects.

- The results of these evaluations have an impact on undertaken development decisions regarding the implementation of innovations and initiation of organizational changes. A stream of these changes creates new knowledge in an enterprise.

Identified areas of knowledge are included in a Knowledge Map.

\subsection{Knowledge Map structure}

The proposed map emphasizes seven domains of knowledge which are crucial, according to the authors, for appropriate enterprise management in the construction industry, namely: System and environment; Assets and resources; Processes; Documents; Completed and ongoing projects; Analysis and corrections and also Lessons learned. In every domain of knowledge, three elements of knowledge have been specified (Hoła, Polak 2011). Figure 5 presents a fragment of a computer screen, in which the structure of the proposed Knowledge Map is shown. The computer program Knowledge Map was created with the use of Access technology. Clicking with the mouse in the appropriate element of the Knowledge Map enables information to be obtained about a higher level of accuracy.

\subsubsection{System and environment}

The first domain which is described as "System and environment" is used to identify a construction company and its business environment. This domain includes knowledge about the area of an enterprise's business activity, organizational structure of an enterprise, departments, institutions and enterprises with whom cooperation stem, either from current laws or due to business or research reasons.

\subsubsection{Assets and resources}

The second domain of knowledge includes information about assets and resources which belong to an enterprise. It is used to identify human resources and also tangible and intangible assets of an enterprise. Human resources consist of: management, engineering and technical staff, office workers and construction workers. The tangible resources include: possessed machines, devices and tools and also buildings objects. The intangible resources include: trademarks, utility models, inventions and patents and works protected by copyright.

\subsubsection{Processes}

A set of processes included in the domain "Processes" has been divided into three subsets, namely a subset of main, auxiliary and management processes. A subset of main processes includes processes occurring in the construction investment process. Auxiliary processes are related to the subject of production through performed service functions and include purchases, tests and inspections. Management processes include processes that occur in any enterprise regardless of the type of business activity. It includes: staff management, resources, finances and risk processes and also management in the field of tactical supervision and in the area of general administration. Figure 6 presents an exemplary expansion of the element of "Main Processes". At the lowest level of this expansion, a detailed procedure of a sought after process can be found; information about documents required to initi- 


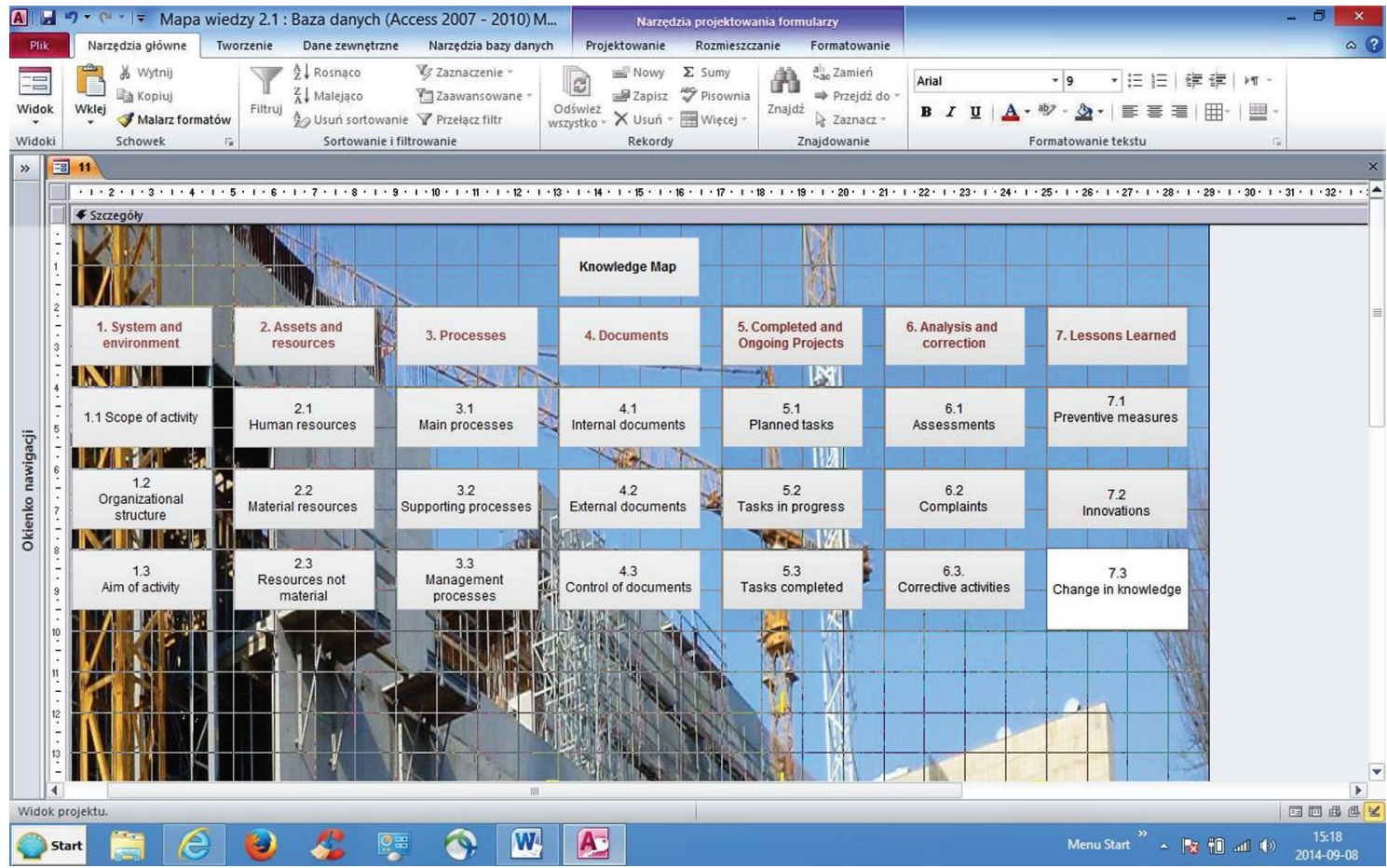

Fig. 5. A fragment of a computer screen which presents a scheme of the structure of the Knowledge Map

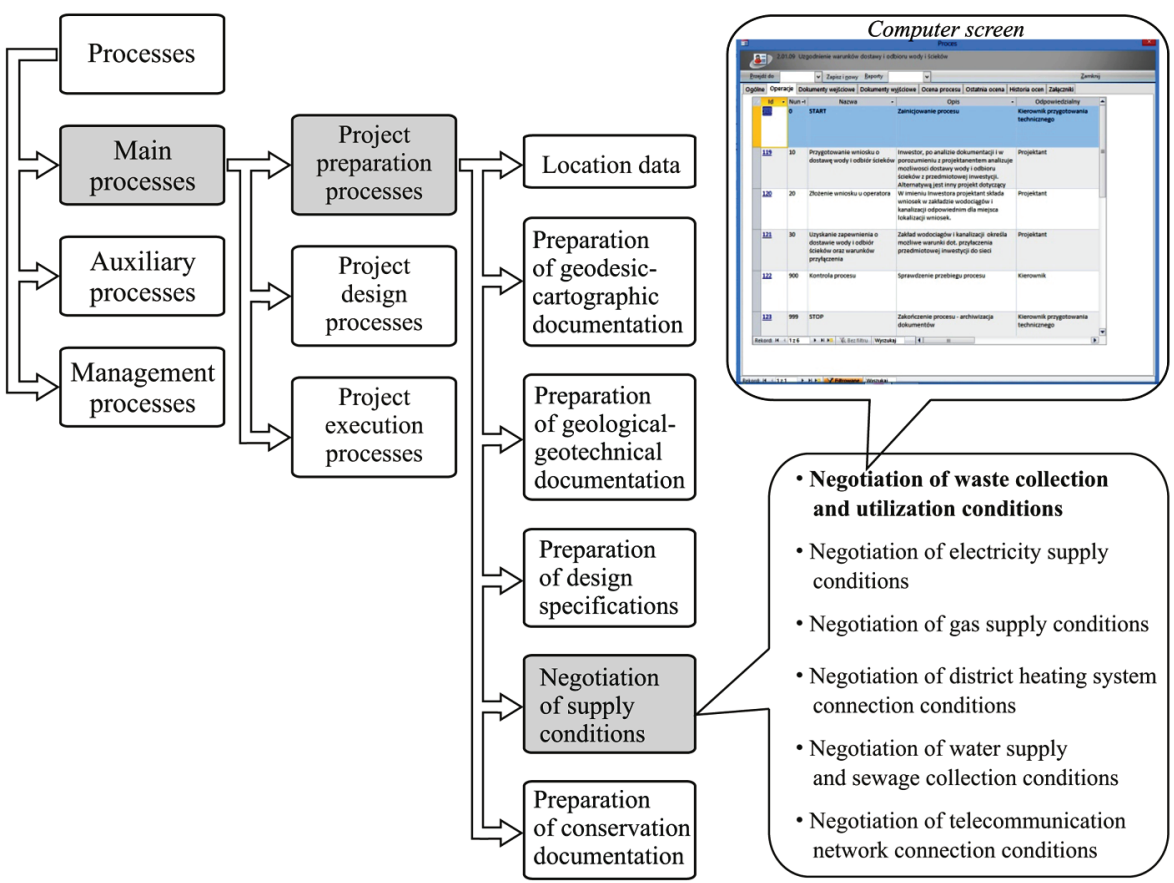

Fig. 6. An expansion of the knowledge element "Main Processes"

ate a process and created in the course of the process and also information about people responsible for the course of a process.

The correct identification of processes occurring in an organization and the links and interactions between them enables subsequent monitoring, supervision and process improvement. The prototype of the Knowledge
Map includes a set of eighty-one model procedures of processes occurring in Polish construction enterprises.

\subsubsection{Documents}

The "Documents" domain has been divided into three subsets. The first subset is formed from internal documents which are created in a construction enterprise 
such as: work instructions, orders, reports, notes from meetings etc. The second subset contains external documents required by laws such as: legal acts, regulations and standards. The third subset called "Supervision of documents" specifies people who are responsible for creating, supervising, approving and storing documents. In this domain, a user of the system will also find the forms and formats of the typical documents found in a construction enterprise and also references in the form of a link to websites from where current applicable laws, regulations and forms can be downloaded. The prototype of the Knowledge Map contains a list of about 300 documents occurring in civil engineering and examples of selected documents. During the implementation of the Knowledge Map in an enterprise, a set of processes and documents related to them are adapted to the needs of the enterprise.

\subsubsection{Completed and ongoing projects}

"Completed and ongoing projects" is a very important domain which gives a Knowledge Map its dynamic character. In this domain, sets of processes occurring in each project executed by an enterprise are formulated. On the basis of control questions, it is possible to group processes for each construction project. The result of grouping is a set of processes related to the implementation of a specific customer order. Along with processes, required documents and responsibilities of personnel involved in the project are automatically generated. In this module a system user will find information about construction projects already completed, in the phase of implementation or planned for implementation. They can be seen as examples for identical or similar subsequent projects.

\subsubsection{Analysis and corrections}

The "Analysis and corrections" domain includes the following components: assessment of suppliers, employees and processes; complaints and corrective actions. The evaluation of suppliers, employees and processes is carried out according to the category of quality, well-known in the quality engineering rating method proposed by Kolman (2004). For each evaluated object, evaluation criteria, coefficients of importance of each criteria and the interval of ratings assigned to each criterion have been specified. The final score of an evaluation is calculated using the formula:

$$
K_{i}=\frac{\sum_{i=1}^{m} w_{i, j} \times k_{i, j}}{\sum_{i=1}^{m} w_{i, j}},
$$

where: $m$ is the number of criteria; $j$ is the next criterion; $w_{i, j}$ - are coefficients of importance of criterion $j$ for the object $i ; k_{i, j}-$ is evaluation of the criterion $j$ for the object $i$.

Very important for the appropriate functioning of an enterprise in the construction market is information contained in other elements of the "Analysis and correc- tions" domain which relate to reported complaints and introduced corrections. The register of complaints will provide a source of information on the quality of provided services and also indicate areas requiring corrections in both quality of services and enterprise management.

\subsubsection{Lessons learned}

The last very important domain included in the Knowledge Map refers to "Lessons learned". All achievements resulting from the implementation of construction projects, individual and group experiences, applications of employee's ideas, suggestions for improvement and also innovations and changes resulting from them are recorded here. It can be concluded that the condition for the existence of a knowledge management system is the identification and registration of development contents (innovations and changes). The "Lessons learned" domain contains a record of: preventive actions and innovations and also an element called "Change of knowledge state" which is used to estimate knowledge values gained in the analyzed period of time.

Figure 7 shows a scheme of the process of acquiring knowledge based on a construction project. The process starts with the selection of processes for a particular project and ends with the collection of results and evaluation. Processes included in the project are selected from a set of exemplary processes included in the "Processes" domain. Evaluations are carried out on the basis of the course of the project. Results of the evaluation are used for making development decisions which generate changes aimed to the application of knowledge gained on the basis of the project. All changes are recorded in the Knowledge Map. The primary objective of initiating changes is an achievement of a better market position of construction services.

A very important and discussed issue is the measurement of knowledge. Measurement methods of knowledge have been proposed in studies (Arif et al. 2009, 2012; Wen 2009; Gruszczyńska-Malec, Rutkowska 2011). In this research it was assumed that the following evidence will state whether knowledge is created in an enterprise, such as: reported innovations and also preventive and corrective actions. Knowledge may also diminish. It

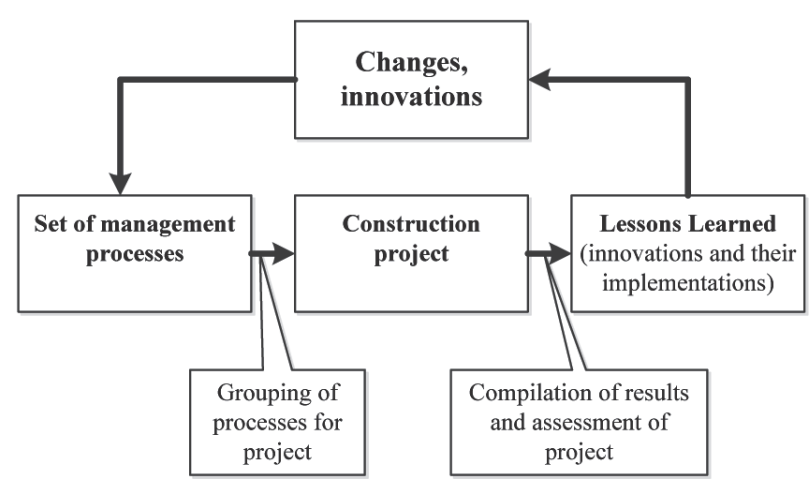

Fig. 7. A scheme of the process of acquiring knowledge 
was assumed that this phenomenon may be confirmed by provided complaints. In order to evaluate an increase of knowledge in a specified period of time, the number of such events and coefficients of importance of these events are taken into consideration. The level of generated knowledge in a specified period of time is determined by the following formula:

$$
W=\frac{\sum\left(l_{k} w_{k}+l_{z} w_{z}+l_{i} w_{i}-l_{r} w_{r}\right)}{w_{k}+w_{z}+w_{i}+w_{r}},
$$

where: $l_{k}-$ is the number of corrective actions; $k=1$, ..., $K ; w_{k}-$ is the coefficient of importance of corrective actions; $l_{z}-$ is the number of preventive actions, $z=1$, ..., $Z ; w_{z}$ - is the coefficient of importance of preventive actions; $l_{i}-$ is the number of innovative actions; $i=1$, ..., $I ; w_{i}-$ is the coefficient of importance of innovative actions; $l_{r}$ - is the number of complaints; $r=1, \ldots, R ; w_{r}-$ is the coefficient of importance of complaints.

\subsection{Implementation and validation of the Knowledge Map in enterprises}

The Knowledge Map was implemented in two construction enterprises, namely, in executive enterprise A and project enterprise B. Enterprise A conducts activities which consist of constructing new buildings and renovating existing ones. Economic activity is carried out in the area of the whole country, but most projects are carried out in Lower Silesia. Enterprise B performs comprehensive project documentations in the field of transport construction. Project documentations are prepared in all possible stages. In addition to design works, the enterprise also performs surveying and geotechnical works, studies in the field of environmental protection, study works, economic analysis, tender documentation and other specialized elaborations.

During implementation the program was installed on computers selected by owners, information about the enterprise was introduced and changes in the program involving the adaptation of the Knowledge Map contents, especially the adaptation of conducted processes to the specificity of the enterprise, were implemented. Exemplary evaluations of employees, suppliers and processes were also executed.

Figure 8 shows exemplary results of the evaluation of the process "purchase of auxiliary materials" which was carried out in semi-annual periods of time. The results of evaluations obtained in subsequent periods, presented in the chart, show the development trend of the quality level of the assessed process. A fragment of a computer screen presented in Figure 8 shows the methodology of process evaluation in the computer version.

The history of evaluations of the assessed process which is shown in the chart indicates that in the first year, from the moment of the implementation of the evaluation system, the level of process quality increased but did not reach an advantageous level above $70 \%$. In the subse-

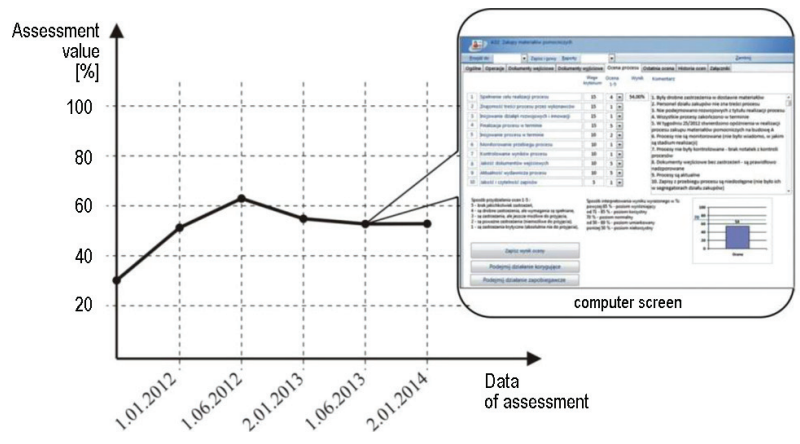

Fig. 8. An example of process evaluation

quent examined time periods a decline of the value of the process quality coefficient is noticeable. In the middle of the second year and at the end of the second year, an evaluation result of only $54 \%$ was obtained. This indicates a moderate level of quality which is close to the disadvantageous level.

Due to a graphic illustration of the phenomenon, changes occurring in evaluations can be observed, trends can be analyzed and reasons for these changes can be investigated. Works used to verify the developed model under various conditions of enterprise operation are currently being carried out.

\section{Conclusions}

The presented model of the Knowledge Map was built based on the results of research and analysis carried out in small and medium-sized construction enterprises in Poland. It was assumed that the Knowledge Map will be based on a process approach to management which is recommended in ISO standards related to quality management. Based on the conducted research, typical primary (executive), auxiliary and management processes occurring in construction enterprises were defined. The results of carried out audits enabled the formulation of procedures of model management processes in accordance with the recommendations of ISO standards and the identification of documents related to these processes.

The proposed Knowledge Map consists of the following seven domains of knowledge: System and environment; Assets and resources; Processes; Documents; Completed and on-going projects; Analysis and corrections and also Lessons learned. Moreover, each domain of the Knowledge Map consists of three elements. After implementation and application in an enterprise, the Knowledge Map will possess assets of information regarding:

- an appropriate course of all the processes occurring in an enterprise and also information about documents related to these processes - required to initiate a process and created during a process;

- completed construction projects which can be used as templates for the execution of the same or similar projects;

- suppliers and subcontractors, and especially results of their evaluations which will be useful to select suppliers and subcontractors for future projects; 
- evaluations of employees, which will enable to verify if an employee is active, what value he provides to an enterprise and whether the employee should be rewarded.

The Knowledge Map has a universal character which means that it is able to be implemented in construction enterprises with different scopes of building activity. This is due to the possibility of flexible formulation of a set of developed processes in accordance with the requirements of ISO 9001 (2008) standards and documents related to them, depending on the needs of an enterprise. Activities recorded in the Knowledge Map with a developmental character will enable the evaluation of changes in the knowledge state of an enterprise in specified time intervals, which can be an indicator of a company's development.

The developed IT system was implemented in two construction enterprises providing services in the area of designing and executing building structures. Conclusions drawn from the course of the process implementation and consultations carried out in enterprises enabled the future direction of works to be indicated.

\section{References}

Arif, M.; Egbu, C.; Alom, O.; Khalfan, M. 2009. Measuring knowledge retention: a case study of a construction consultancy in the UEA, Engineering Construction and Architecture Management 16(1): 92-108. http://dx.doi.org/10.1108/09699980910927912

Arif, M.; Khalfan, M.; Bernard J. H.; Heller, N. A. 2012. Assessing knowledge retention in construction organisations: casus from the UAE, Australasian Journal of Construction Economics and Building 12(2): 55-71. http://dx.doi.org/10.5130/ajceb.v12i2.2461

Bitarafan, M.; Hashemkhani Zolfani, S.; Arefi, S. L.; Zavadskas, E. K. 2013. Evaluating the construction methods of cold-formed steel structures in reconstructing the areas damaged in natural crises, using the methods AHP and COPRAS-G, Archives of Civil and Mechanical Engineering 12(3): 360-367.

http://dx.doi.org/10.1016/j.acme.2012.06.015

Burati, J. L.; Oswald, T. H. 1993. Implementing TQM in engineering and construction, Journal Management in Engineering 9(4): 456-470.

http://dx.doi.org/10.1061/(ASCE)9742-597X(1993)9:4(456)

Cheng, M.-Y.; Peng, H.-S.; Huang, C.-M.; Chen, C.-H. 2012. $\mathrm{KM}$ oriented business process reengineering for construction firms, Automation in Construction 21(1): 32-45. http://dx.doi.org/10.1016/j.autcon.2011.05.010

Czarnigowska, A.; Sobotka, A. 2013. Time-cost relationship for predicting construction duration, Archives of Civil and Mechanical Engineering 13(4): 518-526.

http://dx.doi.org/10.1016/j.acme.2013.05.004

Dave, B.; Koskela, L. 2009. Collaborative knowledge management - A construction case study, Automation in Construction 18(7): 894-902. http://dx.doi.org/10.1016/j.autcon.2009.03.015

Davenport, T. H.; Prusak, L. 1998. Working knowledge: how organisations manage what they know. Boston: Harvard Business School Press. 224 p.

Egbu, C. 2006. Knowledge production and capabilities - their importance and challenges for construction organizations in China, Journal of Technology Management in China 1(3): 304-321. http://dx.doi.org/10.1108/17468770610704967
El-Diraby, T. E.; Zhang, J. 2006. A semantic framework to support corporate memory management in building construction, Automation in Construction 15(4): 504-521. http://dx.doi.org/10.1016/j.autcon.2005.07.005

Forcada, N.; Fuertes, A.; Gangolells, M.; Casals, M.; Marcarulla, M. 2012. Knowledge management perceptions in construction and design companies, Automation in Construction 29: 83-91.

http://dx.doi.org/10.1016/j.autcon.2012.09.001

Gabrielaitis, L.; Baušys, R. 2006. Electronic document management in building design, Journal of Civil Engineering and Management 12(2): 103-108.

Galant, V.; Perechuda, K. 2005. Methods and models of managing information and knowledge. Scientific Work No 1086. Wyd. Akademii Ekonomicznej, Wrocław, Poland (in Polish).

Gruszczyńska-Malec, G.; Rutkowska, M. 2011. Effectiveness of knowledge management - indicators and methods of measurement, Przeglad Organizacji 1: 20-23 (in Polish).

Han, S. B.; Sim, K. L.; Ebrahimpour, M. 2012. Relationships among ISO 9001, competitive dimensions and profitability, International Journal of Services and Operations Management 11(2): 222-236.

http://dx.doi.org/10.1504/IJSOM.2012.045200

Haponava, T.; Al-Jibouri, S. 2010. Influence of process performance during the construction stage on achieving endproject goals, Construction Management and Economics 28(8): 853-896.

http://dx.doi.org/10.1080/01446193.2010.487535

Hoła, B.; Polak, A. 2011. Knowledge map for construction company, Przeglad Budowlany 11: 73-76 (in Polish).

Hoła, B.; Polak, A.; Gronowicz, W. 2012a. Knowledge map supporting management in construction companies, in Proc. of International Scientific Conference "People, Buildings and Environment 2012", 7-9 November 2012, Brno University of Technology, Brno, Czech Republic, 164-172.

Hoła, B.; Polak, A.; Sawicki, M.; Gawron, K.; Morka, M.; Skibniewski, M. 2012b. Knowledge maps for small and medium-sized construction firms, in Proc. of Creative Construction Conference, June 30 - July 3 2012, Budapest, Hungary, 252-262.

Hoła, B.; Polak, A.; Sawicki, M.; Gawron, K. 2012c. Process management in construction, Przeglad Budowlany 9: 5558 (in Polish).

ISO 10006:2005 Quality management systems. Guidelines for quality in management in projects. Warsaw: Polski Komitet Normalizacyjny. 44 p. (in Polish).

ISO 9001:2008 Quality management systems. Requirements. Warsaw: Polski Komitet Normalizacyjny. 27 p. (in Polish).

Jaskowski, P.; Sobotka, A. 2012. Using soft precedence relations for reduction of the construction project duration, Technological and Economic Development of Economy 18(2): 262-279. http://dx.doi.org/10.3846/20294913.2012.666217

Jemielniak, D.; Koźminski, A. K. 2012. Knowledge management: Fad or enduring organizational concept?, in D. Jemielniak, A. K. Koźminski (Eds). Handbook of research on knowledge-intensive organizations. Information Science Reference, Hershey, New York, 552-561.

Johannessen, J.-A. 2008. Organisational innovation as part of knowledge management, International Journal of Information Management 28(5): 403-412. http://dx.doi.org/10.1016/j.ijinfomgt.2008.04.007

Kaklauskas, A.; Zavadskas, E. K.; Kazokaitis, P.; Bivainis, J.; Galiniene, B.; D'amato, M.; Naimaviciene, J.; Urbanaviciene, V.; Vitas, A.; Cerkauskas, J. 2013. Crisis management model and recommended system for construction and real estate, Studies in Computational Intelligence 457: 333-343. http://dx.doi.org/10.1007/978-3-642-34300-1_32 
Kale, S.; Karaman, A. E. 2012. Benchmarking the knowledge management practices of construction firms, Journal of Civil Engineering and Management 18(3): 335-344. http://dx.doi.org/10.3846/13923730.2012.698910

Kim, S.; Suh, E.; Hwang, H. 2003. Building the knowledge map: an industrial case study, Journal of Knowledge Management 7(2): 34-45. http://dx.doi.org/10.1108/13673270310477270

Kolman, R. 2004. Knowledge acquisition. Bydgoszcz-Gdańsk: Oficyna Wydawnicza Branta. 128 p. (in Polish).

Koulinas, G. K.; Anagnostopoulos, K. P. 2013. A new tabu search-based hyper-heuristic algorithm for solving construction levelling problems with limited resource availabilities, Automation in Construction 31(2): 169-175. http://dx.doi.org/10.1016/j.autcon.2012.11.002

Lee, M. H.; Tserng, H. P. 2006. Knowledge map apply to junior engineer in construction industry, in Proc. of $23^{\text {rd }}$ International Symposium on Automation and Robotics in Construction (ISARC 2006), 3-5 October 2006, Tokyo, Japan, 746-750.

Lin, Y.-C. 2006. Developing construction assistant experience management system using people-based maps, Automation in Construction 17(8): 975-982. http://dx.doi.org/10.1016/j.autcon.2008.04.004

Lin, Y.-C. 2008. Developing construction assistant experience management system using people-based maps, Automation in Construction 17(8): 350-361. http://dx.doi.org/10.1016/j.autcon.2008.04.004

Lin, Y.-C. 2013. Construction network-based interface management system, Automation in Construction 30(1): 228-241. http://dx.doi.org/10.1016/j.autcon.2012.11.025

Lin, Y.-C.; Wang, L. C.; Tserng, H. P. 2006. Enhancing knowledge exchange through web map-based knowledge management system in construction: lessons learned in Taiwan, Automation in Construction 15(6): 693-705. http://dx.doi.org/10.1016/j.autcon.2005.09.006

Lin, L.-K.; Chang, C.-C.; Lin, Y.-C. 2011. Structure development and performance evaluation of construction knowledge management system, Journal of Civil Engineering and Management 17(2): 184-196. http://dx.doi.org/10.3846/13923730.2011.576833

Liu, L.; Li, J.; Lv, C. 2009. A method for enterprise knowledge map construction based on social classification, System Research and Behavioral Science 26(2): 143-153. http://dx.doi.org/10.1002/sres.960

Maqsood, T.; Finegan, A.; Walker, D. 2006. Applying project histories and project learning through knowledge management in an Australian construction company, Learning Organization 13(1): 80-95. http://dx.doi.org/10.1108/09696470610639149

Negahban, S. S.; Baecher, G. B.; Skibniewski, M. J. 2012. A decision-making model for adoption of enterprise resource planning tools by small-to-medium size construction organizations, Journal of Civil Engineering and Management 18(2): 253-264. http://dx.doi.org/10.3846/13923730.2012.666503

Nonaka, I.; Takeuchi, H. 1995. The knowledge creating company: How Japanese companies create the dynamics of innovation. Oxford: Oxford University Press. 284 p.

O'Donell, A. M. 1993. Searching for information in Knowledge maps and text, Contemporary Educational Psychology 18(2): 222-239. http://dx.doi.org/10.1006/ceps.1993.1018

O’Donell, A. M. 1994. Learning from Knowledge Maps: the effects of map orientation, Contemporary Educational Psychology 19(1): 33-44.

http://dx.doi.org/10.1006/ceps.1994.1004

Pathirage, C. P.; Amaratunga, D. G.; Haigh, R. P. 2007. Tacit knowledge and organizational performance: construction industry, Journal of Knowledge Management 11(1): 115126. http://dx.doi.org/10.1108/13673270710728277
Pheng, L. S.; Teo, J. A. 2000. Implementing total quality management in construction firms, Journal of Management in Engineering 20(1): 8-15. http://dx.doi.org/10.1061/(ASCE)0742-597X(2004)20:1(8)

Preece, K.; Moodley, K.; Hyde, J. 2000. Knowledge management strategies to improve construction business development processes - a preliminary case study, in Proc. of $6^{\text {th }}$ Annual ARCOM Conference, 6-8 September 2000, Glasgow Caledonian University, Association of Researchers in Construction Management. Vol. 1, 325-334.

Rezgui, Y. 2006. Ontology-cantered knowledge management using information retrieval techniques, Journal of Computing in Civil Engineering 20(4): 261-270. http://dx.doi.org/10.1061/(ASCE)0887-3801(2006)20:4(261)

Rezgui, Z.; Hopfe, C.; Voraculpipat, C. 2010. Generations of knowledge management in the architecture, engineering and construction industry: an evolutionary perspective, Advanced Engineering Informatics 24(2): 219-228. http://dx.doi.org/10.1016/j.aei.2009.12.001

Soares, J.; Anderson, S. 1997. Modeling process management in construction, Journal of Management in Engineering 13(5): 45-53. http://dx.doi.org/10.1061/(ASCE)0742-597X(1997)13:5(45)

Staniūnas, M.; Medineckienė, M.; Zavadskas, E. K.; Kalibatas, D. 2013. To modernize or not: Ecological-economical assessment of multi-dwelling houses modernization, Archives of Civil and Mechanical Engineering 13(1): 8898. http://dx.doi.org/10.1016/j.acme.2012.11.003

Tam, W. Y. V.; Le, K. N.; Le, H. N. 2008. Using Guassian and hyperbolic distributions for quality improvement in construction: case study approach, Journal of Construction Engineering and Management 134(7): 555-561. http://dx.doi.org/10.1061/(ASCE)0733-9364(2008)134:7(555)

Tchidi, M. F.; He, Z.; Li, Y. B. 2012. Process and quality improvement using SIX SIGMA in construction industry, Journal of Civil Engineering and Management 18(2): 158-172. http://dx.doi.org/10.3846/13923730.2012.657411

Tserng, H. P.; Yin, S. Y.-L; Lee, M.-H. 2010. The use of knowledge map model in the construction industry, Journal of Civil Engineering and Management 16(3): 332-334. http://dx.doi.org/10.3846/jcem.2010.38

Tserng, H. P.; Lin, Y. C. 2004. Developing an activity-based knowledge management system for contractors, Automation in Construction 13(6): 781-802. http://dx.doi.org/10.1016/j.autcon.2004.05.003

Wen, Y. F. 2009. An effectiveness measurement model for knowledge management, Knowledge-Based Systems 22(5): 363-367. http://dx.doi.org/10.1016/j.knosys.2009.02.007

Wexler, M. 2001. The who, what, and why of knowledge mapping, Journal of Knowledge Management 9(3): 249-263. http://dx.doi.org/10.1108/EUM0000000005868

Woo, J. H.; Clayton, M. J.; Johnson, R. E.; Flores, B. E.; Ellis, C. 2004. Dynamic Knowledge map: reusing experts tacit knowledge in the AEC industry, Automation in Construction 13(2): 203-207. http://dx.doi.org/10.1016/j.autcon.2003.09.003

Wu, J.-W.; Tseng, J. C. R.; Yu, W.-D.; Yang, J.-B.; Lee, S.-M.; Tsai, W.-N.; 2012. An integrated proactive Knowledge management model for enhancing engineering services, Automation in Construction 24(1): 81-88. http://dx.doi.org/10.1016/j.autcon.2012.02.006

Xu, C. Z.; Ibrahim, T. I. 2004. A keyword-based semantic prefetching approach in internet news services, IEEE Transactions on Knowledge and Data Engineering 16(5): 601-611. http://dx.doi.org/10.1109/TKDE.2004.1277820

Yang, J.-B. 2007. Developing a knowledge map for construction scheduling using a novel approach, Automation in Construction 16(6): 806-815. http://dx.doi.org/10.1016/j.autcon.2007.02.005 
Yin, S. Y. L.; Tserng, H. P.; Tsai, M. D. 2005. A model of integrating the cycle of construction knowledge flows: lessons learned in Taiwan, Automation in Construction 17(5): 536-549. http://dx.doi.org/10.1016/j.autcon.2007.10.002

Yu, W.-D.; Chang, P.-I.; Yao, S.-H.; Liu, S.-J. 2009. KVAM: model for measuring knowledge management performance of engineering community of practice, Construction Management and Economics 27(8): 733-747. http://dx.doi.org/10.1080/01446190903074978

Yu, W.-D.; Yang, J.-B.; Tseng, J. C. R.; Liu, S.-J.; Wu, J.-W. 2010. Proactive problem-solver for construction, Automation in Construction 19(6): 808-816. http://dx.doi.org/10.1016/j.autcon.2010.05.003

Zavadskas, E. K.; Turskis, Z.; Vilutiene, T. 2010. Multiple criteria analysis of foundation instalment alternatives by applying Additive Ratio Assessment (ARAS) method, Archives of Civil and Mechanical Engineering 10(3): 123141. http://dx.doi.org/10.1016/S1644-9665(12)60141-1
Zavadskas, E. K.; Turskis, Z.; Tamosaitiene, J. 2011. Selection of construction enterprises management strategy based on the SWOT and multi-criteria analysis, Archives of Civil and Mechanical Engineering 11(4): 1063-1082. http://dx.doi.org/10.1016/S1644-9665(12)60096-X

Zavadskas, E. K.; Vilutiene, T.; Turskis, Z.; Šaparauskas, J. 2013. Multi-criteria analysis of projects' performance in construction, Archives of Civil and Mechanical Engineering 14(1): 114-121. http://dx.doi.org/10.1016/j.acme.2013.07.006

Zhang, L.; He, J.; Zhou, S. 2013. Sharing tacit knowledge for integrated project team flexibility: Case study of integrated project delivery, Journal of Construction Engineering and Management 139(7): 795-804. http://dx.doi.org/10.1061/(ASCE)CO.1943-7862.0000645

Bożena HOLA. Profesor of Civil Engineering at Wrocław University of Technology, Poland. Working in the Institute of Building Engineering at WUT, she has spent over 35 years doing research on construction process modeling, the managerial approach and safety and health protection at work. She is the author and co-author of two books, over 100 other publications as well as a lot of research and technical reports. She is a member of PZITB (Polish Association of Civil Engineers and Technicians).

Marek SAWICKI. (PhD, Eng) Assistant Professor in the Civil Engineering Faculty at Wrocław University of Technology, Poland. $\mathrm{He}$ is the author and co-author of one book, over 100 other publications as well as a lot of research and technical reports He is a member of the Polish Association of Civil engineers and Technicians (PZITB), Research interests include construction process modeling, the managerial approach and safety and health protection at work.

Mirosław J. SKIBNIEWSKI. Professor of Construction Engineering and Project Management at the University of Maryland (College Park), USA. A past winner of the U.S. National Science Foundation Presidential Young Investigator Award, the Walter L. Huber Research Prize from the American Society of Civil Engineers and a foreign member of the Russian Academy of Engineering. A holder of an honorary doctorate from Vilnius Gediminas Technical University in Lithuania. An author or co-author of over 200 technical publications. Research interests include automation and information technology issues related to construction project engineering and management. 